\title{
Collective Medical Student Perspective on the Importance of Clinical Placements in Medical Education
}

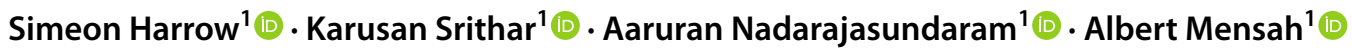

Accepted: 27 September 2021 / Published online: 5 October 2021

(c) International Association of Medical Science Educators 2021

\section{Dear Editor,}

We have reviewed the article "Student Doctors: Learning from the Front Line" [1], which provides an insight into the views of medical students' learning whilst on clinical placements during COVID-19. As current final year medical students, we would like to discuss our learning experiences at hospitals affiliated with King's College London during COVID-19.

We acknowledge that there has been a large change in the delivery of lectures and small group teaching using online platforms due to COVID-19. However, King's College London has made every effort to ensure that fourth and fifth-year students are able to attend clinical placements, where inperson teaching was maintained. This was further supported with weekly small group online teaching. In addition, we agree through our own experiences on clinical placements, that we learn best and retain more information through application of knowledge to clinical scenarios. The General Medical Council guidelines highlight the importance of applying taught material and simulations to clinical practice [2].

We believe that only through a variety of clinical placements can medical students truly learn and appreciate the application of knowledge to clinical practice. Hence we agree with the authors that more clinical placements can indeed provide imperative opportunities for learning [1]. We agree that longer clinical placements working closely with newly qualified junior doctors would help immensely in gaining confidence and becoming more comfortable with the jobs we will soon encounter as junior doctors, which was not commented on by the authors. We feel that there is a significant shift in responsibility from being a medical student to working more independently as a junior doctor. However, if medical students are given the opportunity to immerse into

Simeon Harrow

Simeon.Harrow@kcl.ac.uk

1 GKT School of Medical Education, King's College London, London, UK the jobs of junior doctors early on, whilst being well supported, this will facilitate a smooth transition from medical student to junior doctor. One such example supporting our reasoning is of the experience of final year students who elected to undertake a foundation interim year 1 , for whom exposure to working conditions aided growth in confidence and competence for their foundation posts [3].

Ultimately, the learning experiences gained from clinical placements are invaluable in preparing medical students for the roles and responsibilities of a junior doctor [4]. Therefore, it is of great importance that medical students safely develop history taking, examination and clinical skills, through a number of well-supported clinical placements, particularly in the later years of medical school.

Acknowledgements The authors alone are responsible for drafting and producing the article.

\section{Declarations}

Competing Interests The authors declare no competing interests.

\section{References}

1. Checkley EW, Prosser CJ, Sandler RD. Student doctors: learning from the front line. Medical Science Educator. 2021;2:1-2.

2. General Medical Council (GMC). Good Medical Practice. GMC, 2013 (https://www.gmc-uk.org/-/media/documents/good-medicalpractice---english-20200128_pdf-51527435.pdf?la=en\&hash= DA1263358CCA88F298785FE2BD7610EB4EE9A530 [Accessed on 18th September 2021]).

3. Jones I, Neal-Smith G. FiY1: A reflective account of the foundation interim year 1 post. Clinical Medicine. 2021;21(3):e269.

4. Enoch TR, Williams RC. Why face-to-face medical education will prevail despite the world's swift acclimatisation to virtual learning. Postgraduate Medical Journal. 2021.

Publisher's Note Springer Nature remains neutral with regard to jurisdictional claims in published maps and institutional affiliations. 